\title{
Human Function of Physical Culture
}

\author{
Vasyl Sutula* \\ Kharkiv State Academy of Physical Culture, Ukraine \\ *Corresponding author: Vasyl Sutula, Kharkiv State Academy of Physical Culture, Ukraine. \\ To Cite This Article: Vasyl Sutula. Human Function of Physical Culture. Am J Biomed Sci \& Res. 2019 - 1(6). AJBSR.MS.ID.000560. \\ DOI: 10.34297/AJBSR.2019.01.000560
}

Received: March 01, 2019 | Published: March 21, 2019

\section{Opinion}

Physical culture performs in a society a number of general and special functions that are implemented in the form of specialized activities of people associated with the use of physical exercises. Such activity is conditioned by the necessity of using physical exercises in the process of individual development of a person (physical education) [1,2], in the process of carrying out physically active leisure activities (physical recreation, fitness) [3], in the process of self-expression through adventure activity (sport) [4,5], as well as in other related forms of social practice. In addition to the above-mentioned special functions, physical culture as a special kind of universal culture, performs in society and an integral (human-generating) function, that is, a function that is inherent in all forms of social manifestation of physical culture which determines its integrity. The realization of this function in a social environment has its own peculiarities. Its analysis in modern studies occupies a special place [6].

It is considered, so to speak, in two planes. On the one hand, the influence of physical culture on the spiritual sphere of man is investigated. This trend began to develop especially intensively in recent years in connection with the realization that under the influence of physical culture in a social environment specific spiritual values are formed. Their creation, assimilation and multiplication take place in the form of the motor activity of each person as the subject (carrier) of culture, and the very activity of man acts, firstly, as one that creates such values, and secondly, as one that itself along with its results, is an element of the culture of society. On the other hand, human-forming function of physical culture is studied taking into account the influence of physical culture on physical health of a person, on the development of elements and structures of motor activity and morphological and functional systems of his organism.

The problem of man-making function of physical culture, in spite of its versatile study, still has a lot of insufficiently researched aspects. The linguistic function of physical culture cannot be fully understood unless one considers the peculiarities of its influence on the biological and social components of the human being through the prism of their interconnection. This problem requires a special analysis because it is only mentioned in the scientific literature. When studying this problem, it is necessary to answer two main questions. First: Does physical culture, as the sphere of human activity is associated with the use of physical exercises, on the biologically hereditary side of human nature? Second: if so, how is this happening? This is a rather complicated problem that affects the very essence of human existence. Now it is possible to outline only some contours of its solution. It is advisable to rely on two biological laws: first, signs acquired during ontogenesis are not inherited; and secondly, the unit of the evolutionary process is kind of.

If to rely on the first law, one can conclude that the physical perfection of man achieved by her as a result of lengthy exercises physical exercise is not inherited. This means that the culture of motor activity of a particular person and its results, which manifest themselves in changing the level of its physical health and physical fitness, through genetic mechanisms are not passed from generation to generation. From here it would be possible to conclude that physical culture does not affect the biological hereditary side of human nature. However, it is not. Such influence still exists. It has no direct but indirect character and is manifested in the fact that the practical activity of people, carried out within the various forms of social realization of physical culture (physical education, sports, physical recreation, adaptive physical culture, etc.), promotes an increase in the level of physical health concrete person because it improves the functioning of all systems of its organism. This manifests the direct effect of physical culture on the biological nature of a particular person, resulting in favorable conditions for the development of healthy offspring in it.

That's it the action will be of significance from the point of view of the evolution of the species Homo Sapiens only if it covers a sufficiently large number of people, since, as stated in the second of the above-mentioned biological laws, the unit of the evolutionary process is the form. Therefore, in order to formulate sustainable adaptation changes that ensure the transfer of a high 
level of physical health from generation to generation (the social significance of physical culture), physical culture should attract a significant number of people into their sphere of influence (at least during the active reproductive age).

Only in this case, if we consider the actual problem from the standpoint of evolutionary changes in the biological species, there is a socially significant (phylogenetically inherited) health effect from the activities of people associated with the use of physical exercises. One should pay attention to some, at first glance, sufficiently obvious features of the use of physical exercises. On the one hand, systematic human use of such exercises creates favorable conditions for the optimal functioning of all systems of the body, ie directly affects its physical health and physical condition. On the other hand, to induce a person to do physical exercises systematically, which do not have a direct utilitarian significance for him (one-minute direct benefit, benefit), by means of forming the corresponding needs, ie influencing in a certain way his spiritual sphere. Consequently, physical exercises are a kind of core around which combines human motility and its spiritual development in the process of specialized activities.

The described mechanism of influence of various forms of social manifestation of physical culture (physical education, sports, physical recreation and other forms of social practice related to them) to a person as a representative of a biological species is precisely the natural bridge that connects social and biological in its development. He (the mechanism) shows that the unity of all forms of social manifestation of physical culture is manifested not only in the fact that they use the same means (physical exercises), but also in because all of them, involving the broad masses of the population in the activity connected with the use of physical exercises within the framework of a specially organized pedagogical process, create conditions for the formation of sustainable changes aimed at improving the level of physical health and physical (natural) characteristics of a person. Consequently, the human need for health and optimal physical development is a biologically determined, but gradually realized in society and satisfied in it through various forms of social manifestation of physical culture (physical education, sports, physical recreation, etc.).

\section{Conclusions}

i. Based on the above analysis, one can conclude that the integral (system-forming) function of physical culture has two mutually determined faces - pedagogical (educational) and social (health-development).

ii. Human activity associated with the use of physical exercises serves, firstly, as one that creates the values of physical culture, and secondly, as such, which in itself along with its results is an element of the culture of society.

\section{References}

1. Vasyl Sutula (2017) The essence of the connection between physical culture and physical education. The theory and methods of physical education and sport №4: 91-96.

2. Vasyl Sutula (2018) The essence of the connection between physical culture and physical education. The theory and methods of physical education and sport. №1: 78-84.

3. Vasyl Sutula (2016) The essence of the connection between physical culture, physical recreation and physical fitness. The theory and methods of physical education and sport. №4: 77-84.

4. Vasyl Sutula (2018) Cultural and Historical Origins of Modern Sport. Slobozhansky Scientific and Sport Bulletin 2(64): 73-81.

5. Vasyl Sutula (2018) General Definition of the Concept "Sports." Journal of Physical Fitness, Medicine \& Treatment in Sport 4(4).

6. Vasyl Sutula (2017) Conceptual provisions of the generalization theory of physical culture. The theory and methods of physical education and sport №3: 107-115. 